\title{
Face au Concordat (1801), résistances des évêques anciens constitutionnels
}

\section{Bernard Plongeron}

\section{(2) OpenEdition \\ 1 Journals}

\section{Édition électronique}

URL : https://journals.openedition.org/ahrf/1520

DOI : 10.4000/ahrf.1520

ISSN : 1952-403X

Éditeur :

Armand Colin, Société des études robespierristes

\section{Édition imprimée}

Date de publication : 1 septembre 2004

Pagination : 85-115

ISSN : 0003-4436

\section{Référence électronique}

Bernard Plongeron, «Face au Concordat (1801), résistances des évêques anciens constitutionnels », Annales historiques de la Révolution française [En ligne], 337 | juillet-septembre 2004, mis en ligne le 15 septembre 2007, consulté le 22 avril 2022. URL : http://journals.openedition.org/ahrf/1520 ; DOI :

https://doi.org/10.4000/ahrf.1520

Ce document a été généré automatiquement le 22 avril 2022.

Tous droits réservés 


\title{
Face au Concordat (1801), résistances des évêques anciens constitutionnels
}

\author{
Bernard Plongeron
}

1 Malgré des appréciations très positives lors du bicentenaire, le Concordat est loin de ressembler à un long fleuve tranquille, surtout quand on remonte à sa source. Les différentes catégories du haut clergé en fonctions après la Révolution approchent de la rébellion ouverte pour un motif commun: un évêque n'est pas un fonctionnaire révocable à souhait. Il y va de la vie des diocèses qu'ils ont en charge.

2 Première catégorie, les évêques réputés légitimes parce que toujours institués par Rome. Bonaparte a cru régler la question en exigeant du pape Pie VII le bref Tam multa (15 août 1801), par lequel tous les évêques remettraient leur démission, laissant ainsi place nette pour recomposer un épiscopat conforme à ses vues. De tous les pays où ils sont encore émigrés, s'élèvent les véhémentes protestations des prélats contre ce coup de force unique dans les annales de l'Église. À Rome comme à Paris, on fut surpris de l'âpreté et de la longueur des négociations avec les intéressés. Il fallut attendre le 22 décembre pour qu'après de multiples péripéties, on parvienne à un résultat, somme toute médiocre au regard de cet épiscopat soumis au Pape: sur 94 évêques (non compris les 9 exerçant dans les pays réunis), 58 finirent par donner leur démission ; 36 autres s'opposèrent formellement, formant le parti anti-concordataire, avec à leur tête, un cardinal. En effet, Mgr. de Montmorency-Laval, évêque de Metz, en exil à Altona (Allemagne) dans une lettre du 28 octobre 1801, demande roidement au Pape s'il a bien mesuré les conséquences de toutes ces « démissions simultanées ».

« Il ne m'est pas permis d'être indifférent sur le sort futur ni de mon église que j'abandonnerais, ni de l'Église gallicane toute entière qui, par tant de démissions simultanées, se trouverait momentanément éteinte et à l'extinction de laquelle je contribuerais en quittant mon siège. ${ }^{1}$

Une objection dont n'a cure Bonaparte. Les diocèses français ne continuent-ils pas à être administrés par les évêques ex-constitutionnels? Ainsi commence un interminable discours de sourds. Pour Rome et les évêques « légitimes ", ces évêques n'existent pas, 
puisque déclarés "schismatiques ». Bonaparte, lui, continue de les reconnaître : leurs sacres n'ont jamais été déclarés invalides par Rome et on ne reviendra jamais là-dessus par la suite.

C'est à cette seconde catégorie que nous allons nous intéresser, tant elle accumule les difficultés au risque même de compromettre l'œuvre concordataire au long des négociations conflictuelles et tortueuses, débouchant sur une complète confusion entre tous les acteurs du Concordat, au point d'entretenir encore la polémique parmi les historiens.

5 Après la Terreur, il y a encore 59 évêques républicains en charge effective d'un diocèse 2. Ils sont réunis dans le second Concile national à Paris, du 20 juin au 16 août 1801, c'est-à-dire un mois après la signature du Concordat ( 15 juillet), dont certains ont suivi les laborieuses tractations dans les coulisses du pouvoir. Sur ordre du Premier Consul, Fouché est venu demander aux pères conciliaires de cesser immédiatement leurs travaux pour ne point indisposer davantage la légation romaine conduite par Mgr Spina. Une fiction s'ensuivra: pour nombre de ces prélats, le Concile national est seulement « interrompu »... on pourrait le reprendre plus tard!

6 Bonaparte laisse dire : il ne veut surtout pas s'aliéner ces vétérans de la Révolution. Mieux encore, il pense que certains seraient récupérables en vue de l'« amalgame » des différentes personnalités du clergé concordataire. Encore faudrait-il qu'auparavant elles soient «reconnues» par Rome. D'où ce premier coup de théâtre. L'encre de la convention concordataire à peine sèche, il fait pression sur Spina pour obtenir un autre bref concernant cette fois-ci ces « schismatiques".

7 Effarement du légat qui apprend coup sur coup que Bonaparte a, et l'intention de faire entrer ces « intrus » dans l'épiscopat concordataire, et de les faire absoudre des fautes passées par le Pape Pie VII! Telle est l'origine du bref Post multos labores dont les historiens parlent peu. Le cardinal secrétaire d'État, Consalvi, signataire romain du Concordat, de retour à Rome, n'ignore plus rien des arrière-pensées de Bonaparte et de ses conseillers, l'abbé Bernier, expert à pêcher en eaux troubles, de Portalis, resté très gallican, et des politiques de l'ombre, Talleyrand et Fouché.

8 Main de fer dans son gant de velours, le remarquable Consalvi a concocté un texte, qui devrait ruiner, il le sait, les prétentions françaises. Post multos labores exigeait des anciens républicains, éventuellement promus dans le nouvel épiscopat, démission de leur siège actuel, mais aussi rétraction, selon une formule spéciale, de leurs « erreurs passées » à savoir le serment à la Constitution civile du clergé. Bref, une condamnation en bloc de l'œuvre révolutionnaire depuis 1790 jusqu'à 1801.

9 Une bombe, on le devine, dans les rangs français : le Gouvernement et les prélats exconstitutionnels, aussi bien les pressentis que leurs amis qui mènent campagne contre «la cour de Rome », la personne de Pie VII étant toujours révérée. Ce que l'on sait moins, c'est l'histoire compliquée des tractations des diplomaties officielles et officieuses qui s'entremêlent avec le danger permanent d'une mise en échec du Concordat... du Concordat qui, selon l'interprétation française, comprend la Convention de «messidor an $\mathrm{X}$ » et les fameux Articles Organiques, toujours déniés par Rome. Or, les Articles Organiques (spécialement l'article 24) font obligation expresse au clergé de professer et d'enseigner "la déclaration faite par le clergé de France en $1682 »$. Ce retour au gallicanisme va servir de nerf à la contestation des prélats républicains, au grand dam des ultramontains. 
10 Le texte lui-même de Post multos labores prête déjà à des controverses. Il est certain que le bref est arrivé à Paris fin juillet 1801. Il n'est révélé qu'en septembre par Mgr. Spina. Pourquoi ce délai ? Par ailleurs, il existe deux versions : celle dite directe (le texte de Pie VII plutôt chaleureux et bienveillant) et celle indirecte, élaborée à Paris par la légation romaine beaucoup plus rude, assortie d'un formulaire ponctuée de conditions exorbitantes pour une réconciliation.

11 Mais la question principale demeure celle-ci : oui ou non, les anciens constitutionnels intégrés dans l'épiscopat concordataire se sont-ils finalement rétractés, selon les conditions imposées par Rome, pour être pleinement « réconciliés » par le Saint-Siège ? Les historiens répondent par l'affirmative, y compris récemment Rodney J. Dean ${ }^{3}$, malgré quelques précautions, au moins à partir de 1804, lors de la venue de Pie VII à Paris pour le couronnement de Napoléon.

12 Seule une chronologie rigoureuse - elle a souvent un caractère fastidieux qui peut décourager - permet une réponse documentée. Celle-ci exige le croisement des sources: d'une part, celles bien connues, émanant surtout des six volumes des Documents sur la négociation du Concordat et sur les autres rapports de la France avec le SaintSiège, publiés entre 1891 et 1905 par le conseiller d'État, Alfred Boulay de la Meurthe. Cet historien utilisait les papiers de son parent, le comte Antoine-Jacques, confrère de Portalis, donc témoin direct. Il faut y joindre naturellement les Archives Caprara (AF IV). Mais, d'autre part, on doit recourir aux archives de l'Église constitutionnelle, jusqu'ici ignorées des histoires officielles.

13 Dans le cadre d'un article, force est d'admettre certaines simplifications d'une réalité plus mouvante pour privilégier deux moments cruciaux : 1802 et 1804 .

Raisons historiques d'un refus de repentance

14 À peine le Concile national est-il «interrompu » que, le 21 août, une quinzaine d'évêques se retrouvent chez Grégoire pour aviser : parmi eux se détache déjà le parti de la résistance: Grégoire (Blois); Le Coz, président du Concile (Rennes); Lacombe (Bordeaux), vice-président ; Moïse (Saint-Claude) très lié à Grégoire ; Périer (Clermont) ; Reymond (Grenoble), théologien notoire; Debertier (Rodez) qui se retirera à Paris ${ }^{4}$. Aucun ne se montrait disposé à abandonner son diocèse. Tous manifestaient le désir de reprendre le Concile dès que possible : «Plusieurs de ces travaux sont urgents mais la manifestation de votre volonté [Bonaparte] lui a imposé de clore la session. Les membres qui la composaient offrent, par leur conduite passée, la garantie des sentiments religieux et civiques dont ils ont été toujours animés». Les jours suivants furent consacrés à la mise en forme d'un mémoire, Observations de membres du Concile sur le Traité avec Rome, publié le 28 août ${ }^{5}$. En phrases soigneusement balancées, signées par Le Coz, Grégoire, Moïse, Périer, Debertier et Reymond, les constitutionnels affectaient d'abord d'être "pénétrés de joie » en apprenant que la proclamation du 10 juillet (31 messidor an IX) allait faire cesser les divisions religieuses. Ils ne désespéraient pas d'ouvrir encore une "troisième voie » entre Rome et Paris en suggérant au Premier Consul des compromis très provisoires sur des points essentiels. Ainsi du système électoral du clergé institué par la Constitution civile du clergé.

«Si les circonstances exigent que, pour un temps, on s'en écarte, il nous paraît nécessaire d'y revenir le plus tôt possible. Toutefois, parce qu'il importe que tous ceux qui seront rappelés aux premiers emplois ecclésiastiques soient agréables au gouvernement, nous verrions sans peine, lors même que les saints canons seraient remis en vigueur, que le choix ultérieur des sujets fut laissé au premier magistrat de 
la République sur une présentation que lui en feraient le clergé et les fidèles de chaque diocèse. " Consul. Quant à la délicate question de l'investiture canonique, il eût été préférable de conserver le droit aux "métropolitains" (archevêques) puisque l'histoire de l'Église gallicane prouvait que les papes "s'étaient appropriés ce droit", source d'un despotisme de la "Cour de Rome", toujours distinguée du Souverain Pontife, pour « subjuguer les Églises et les États ». Les signataires du mémorandum savent bien qu'ils touchent un point sensible chez Bonaparte, fermement invité à « rétablir l'ancien droit ecclésiastique " dès que cela sera possible. Le conseil ne sera pas perdu lorsque l'Empereur s'opposera, à partir de 1810, à Pie VII. Pour le moment, par réalisme concordataire, faisons le gros dos.

" Si votre sagesse décide que les libertés de l'Église gallicane doivent être momentanément voilées, qu'elles le soient; mais d'un voile transparent qui les laisse toujours apercevoir, et qui soit un jour facile à déchirer. » touchons au fondement de la résistance continue des constitutionnels. Pour eux, la Constitution civile du clergé et le serment ne sont que les conséquences logiques des libertés de l'Église gallicane contenues dans la Déclarations des Quatre Articles de 1682. Ces libertés sont le rempart inébranlable contre « certains principes désastreux dont la cour romaine est imbue et qui tendent à lui asservir les nations et à renverser toute discipline, tout bon ordre dans l'Église ».

oin d'être une péripétie historique, la Déclaration de 1682 appartient au patrimoine de l'Église de France. Ce n'est pas un hasard si l'ex-Église constitutionnelle s'est proclamée après Thermidor "gallicane » pour s'insérer dans la tradition. Celle-ci est de nouveau brandie dans l'autre crise concordataire de 1817-1821. Dans le camp des libéraux, Portalis fils obtient du Conseil d'État le rétablissement des Articles Organiques, à la grande fureur de Rome qui bloque les négociations en cours. Grégoire en profite pour faire rééditer son Essai historique sur les libertés gallicanes (1820). J. de Maistre réplique, au nom des ultramontains, par son ouvrage De l'Église gallicane (1821). Il ouvre la voie à l'historiographie conservatrice en accréditant la thèse: la Déclaration des Quatre Articles est le fruit d'un jansénisme parlementaire « qui n'est au fond que le calvinisme [...] en affinité avec le jansénisme ». Dès lors, « ils renferment un schisme évident » (pp. 207 ; 256 ; 274). Le vénérable cardinal de Bausset, un ami de M. Emery, se sent dans l'obligation de rectifier dans son Traité sur la Déclaration [...] de 1682 (1822) alors même que, naguère, il avait dénoncé la Constitution civile du clergé :

« Nos maximes sont des articles qui appartiennent à la doctrine que nous professons. Nous pratiquons nos libertés, nous enseignons nos maximes; celles-ci sont le fondement et le boulevard de nos libertés. »

Grégoire exprimait la même « foi » dans sa lettre de démission adressée à ses diocésains de Blois, le 8 octobre 1801 :

«Ces libertés gallicanes, héritages précieux que nous avons reçu de nos ancêtres, que nous devons soutenir jusqu'au dernier soupir et que nous léguerons à ceux qui nous succéderont. ${ }^{6}$

Contre de Maistre qu'il cloue au pilori, en 1821, il rappelle cette anecdote piquante, transparente de l'expérience concordataire de 1801 :

« Douze ecclésiastiques qui avaient assisté à l'assemblée de 1682, ayant été nommés

à des évêchés, sollicitaient leur institution canonique; c'est là que Rome les 
attendait; elle refusa des bulles parce qu'ils refusèrent de rétracter les quatre articles. À la fin tout fut concilié au moyen d'une lettre de soumission au pape, que Bossuet lui-même, que d'Aguesseau et beaucoup d'autres ont prouvé n'être pas une rétractation ; mais $\mathrm{M}$. de Maistre veut absolument qu'elle en soit une. ${ }^{7}$

20

À Rome, on triomphe. Le cardinal Antonelli,
Articles Organiques, exprime sa satisfaction:

"C'est un grand coup donné aux libertés gallicanes. Chacun sait combien les français sont jaloux de ce que la cause de leurs évêques ne soit pas examinée et jugée à Rome en vertu de leurs prétendus privilèges. Or, le Pape, de sa suprême autorité, dépose cinquante ou soixante évêques de leurs sièges et n'en donne d'autre raison que le bien de l'Église [...] Et, par conséquent, à l'avenir, on ne discutera plus pour savoir si le Pape peut déposer un évêque français pour le bien de l'Église. Reste seulement à savoir si sa décision sera exécutée. Mais c'est une controverse de fait et non de droit. »

21 Rome commet ainsi une double erreur de jugement. La première consiste à prendre pour « une controverse de fait » ce qui reste pour les gallicans un débat de fond. La seconde provient d'une indifférence à l'histoire des retombées du formulaire, après la bulle Unigenitus (1713). Les gallicans, opposés à ce formulaire (les "appelants») ont appris à manier la restriction mentale au nom du devoir de conscience. Une pratique transmise jusqu'à la génération des évêques constitutionnels : ils n'inventent pas les fausses sincérités autour des nouveaux formulaires que Rome leur impose.

Surtout quand ils estiment avoir l'appui implicite de leur Gouvernement. Ce n'est pas un hasard si, après les approches de Portalis, de Talleyrand et de Fouché, ils sont conviés à un grand dîner offert par le Premier Consul, le 29 août, à la Malmaison. Il est peu probable que l'affaire des démissions ait été évoquée. À Grégoire, Bonaparte aurait répondu que la chose était prématurée ${ }^{8}$.

Autour du bref post multos labores. Démissions sans rétractation (septembre-octobre 1801)

En revanche, il semble bien que ni le Premier Consul, ni ses conseillers, pourtant à l'affût des activités de la légation pontificale, n'aient eu vent de ce que tramaient les « Romains ».

24 C'est le 29 septembre qu'est présenté, en premier, à Royer (Paris) le fameux bref Post multos labores. Il existait en deux versions. La version, dite directe, celle d'un bref de Pie VII s'adressant aux réputés schismatiques en les traitant de "vénérables frères » et leur adressant, au final, sa bénédiction apostolique. Le Pape les exhortait « à revenir promptement à l'unité, à donner chacun par écrit sa profession d'obéissance et de soumission au Pontife romain et à renoncer aussitôt aux siège épiscopaux dont ils s'étaient emparés sans l'institution du Siège Apostolique ». La version, dite indirecte, s'adressait à Mgr. Spina: il devait demander aux assermentés l'adhésion "aux jugements du Siège Apostolique sur les affaires ecclésiastiques de France ", en clair, la reconnaissance des brefs de Pie VI anathématisant la Constitution civile du clergé et exigeant des prêtres déjà assermentés une rétractation dans les quarante jours.

Seule la version « indirecte » est présentée aux intéressés, laissés dans l'ignorance du texte " paternel » de Pie VII. Le secret est si bien gardé que Grégoire témoigne de sa surprise, en 1810, en consultant les archives romaines saisies par le pouvoir impérial.

"Quelle fut ma surprise en compulsant le règne de Pie VII de ne pas y trouver la circulaire que l'archevêque de Corinthe (Spina) avait envoyée aux évêques assermentés [la version «indirecte » du bref] et d'y trouver la minute d'un bref 
paternel du Pape à ces évêques qui débute par ces mots : Vénérables frères [...] qu'ils n'ont pas reçu et auquel fut substituée la lettre outrageante du cardinal Spina qui, mieux que personne sans doute, pourrait donner le mot de cette énigme. " ${ }^{9}$

On aura compris l'énorme différence entre les deux versions. La version directe est un appel chaleureux au retour à l'unité par une démission simple. La version indirecte engage une rétractation formelle de tous les actes des assermentés depuis 1790. Ce mot même de « rétracté » fait horreur à ces prélats, qui en font une affaire de conscience et d'honneur. Grégoire y insiste dans l'envoi de sa lettre de démission à ses diocésains :

«On sait qu'aux époques où la patrie était menacée de subir le joug de l'étranger, quelques prêtres passèrent du camp d'Israël sous les tentes des Philistins : on les appela rétractés; ce nom imprime une tache ineffaçable à l'espèce d'hommes les plus méprisables dans tous les temps et aujourd'hui les plus embarrassés du personnage qu'ils doivent faire. $»^{10}$

L'indignation est générale et la consternation règne au gouvernement. Il devient évident que Spina, avec un zèle maladroit, a voulu forcer la main de tous les acteurs français du Concordat. Selon la police, une grande effervescence règne dans Paris. Le 4 octobre, arrive le cardinal-légat Caprara dont tous les auteurs admettent qu'il ne sera jamais à la hauteur de la situation, quoiqu'il sera d'une servilité à l'égard de Napoléon Bonaparte, insupportable même aux évêques césaristes. Bonaparte lui signifie sèchement qu'il ne peut laisser ainsi traiter les évêques patriotes. « Les mécontenter est impossible. »

Les démissions sont néanmoins en cours depuis le 8 octobre. Selon les «canons » de l'Église gallicane, Grégoire a remis sa lettre non au légat, comme il était demandé, mais à son métropolitain, Dufraisse (Bourges). On s'agite beaucoup parmi les évêques : Le Coz (Rennes) a dit toute son amertume dans une visite à Portalis, nommé, le 7, Conseiller d'État chargé des cultes : ce principal artisan de la politique concordataire ne tient pas, en effet, à voir s'écrouler l'édifice à cause des embardées de la légation pontificale. Sa nomination n'apaise pas les plus excités: Clément (Versailles), Thuin (Meaux), voudraient la reprise du concile national et cherchent à persuader Grégoire par les lettres pressantes. d'un repentir quelconque et le Moniteur leur donne la publicité officielle pour qu'il n'y ait pas de contestation possible.

30 S'il y a un tel empressement désormais, c'est que Portalis a résolu de fournir un modèle de lettre tel qu'il soit conforme à la loi concordataire et rien de plus ; le légat devra s'en contenter. «D'ailleurs, il est bon de prévenir les querelles théologiques. »

Voici le texte dans la version parue dans le Moniteur du 25 vendémiaire an X (17 octobre 1801). À l'exception de Grégoire et de Moïse qui lui apportent des modifications si hardies qu'elles entraînent le refus du légat, tous les évêques souscrivent moyennant quelques variantes, analysées par Boulay de la Meurthe. Nous indiquons ces variantes en italiques.

« Très Saint père, il n'est ni sacrifice, ni démarche, ni privation qui coûtent au cœur d'un évêque quand le bien de la religion et l'amour de la paix les exigent. Pénétrés de ces religieux sentiments, nous déclarons donner librement, purement et simplement la démission de nos sièges.

Nous vouons à Votre Sainteté, comme successeur légitime de Saint Pierre, obéissance et soumission conformément aux canons et aux saints décrets de 
l'Église. Nous adhérons à la convention relative aux affaires ecclésiastiques de France et aux principes que [votre sainteté] et le Gouvernement y ont consacrés. Notre foi est celle des apôtres. Nous voulons tous vivre [et mourir] dans le sein de l'Église catholique, apostolique et romaine [et dans la communion du Saint-Siège, centre de l'unité]. Tels sont [et ont été] nos sentiments, nos principes et nos vœux. Nous prions Votre Sainteté d'en agréer le témoignage et d'y joindre sa bénédiction apostolique. »

Portalis a donc omis volontairement ce qui heurtait le plus les anciens constitutionnels dans la version indirecte de Post multos labores : les «jugements du Siège Apostolique » sont diplomatiquement remplacés par la «convention [le concordat] relative aux affaires ecclésiastiques de France ». En conséquence, pareil formulaire n'appelle aucune rétractation. L'« obéissance et soumission " au Pape «comme successeur légitime de Saint Pierre " ne font aucune difficulté, depuis l'appel solennel des pères du premier concile national au Pape. La formule est même habile : " conformément aux canons et aux saint décrets de l'Église », ce qui laisse une porte ouverte aux libertés gallicanes.

Vingt-deux évêques ont refusé la formule « dans la communion du Saint-Siège, centre de l'unité » comme attentatoire à leur conviction gallicane. Il est toutefois à remarquer que deux, du parti de la "résistance ", Belmas (Aude) et Reymond (Isère), ratifient le texte in-extenso, ce qui ne leur ferme pas les portes de l'épiscopat concordataire ${ }^{11}$. Car on commence à murmurer très fort que certaines déclarations ne seraient pas exemptes de calcul, au cas où...

C'est probablement une des raisons du raidissement de Grégoire et de son fidèle Moïse (Jura) qui signent conjointement une déclaration à la fois commentaire politique et plus personnel que le formulaire de Portalis. Leur lettre commune est datée du 10 (même jour que Belmas et Reymond) en ce qui concerne l'envoi à Rome, mais du 12 dans la copie remise à Portalis et immédiatement insérée dans les Annales de la Religion.

En présentant leurs démissions dans les termes convenus, les deux évêques tenaient d'abord à souligner que leur ministère procédait d'une "élection libre » et "d'une ordination sainte ». Puis suivait leur soumission commentée « en respectant les saints canons ».

« Pénétrés de reconnaissance pour l'intérêt que le premier Pontife prend à pacifier les dissensions religieuses, nous concevons la douce espérance que l'arrangement [sic] concerté entre Votre Sainteté et le Gouvernement français, relativement aux affaires ecclésiastiques, terminera toutes les divisions et nous ferons tous les efforts pour que la religion et la patrie en recueillent les plus grands avantages.

Notre foi fut toujours celle des Apôtres, à laquelle Dieu nous a fait la grâce de rendre témoignage, même à la vue de l'échafaud. Notre résolution fut toujours de vivre et de mourir dans le sein de l'Église catholique, apostolique et romaine, et dans la communion du Saint-Siège, centre de l'unité. Tels sont nos sentiments, nos principes et nos vœux. Nous prions Votre Sainteté d'en agréer le témoignage et de nous accorder sa bénédiction apostolique [...] F.X. Moïse, ancien évêque de SaintClaude. H. Grégoire, ancien évêque de Blois. »

Faute de procéder à l'explication littérale de texte, que nécessiterait cette déclaration, contentons-nous d'en souligner l'étonnante dialectique entre le « républicain » qui, par prétérition, refuse violemment la version indirecte du Post multos labores et le pseudo-« ultramontain » que semble devenu le très gallican prélat, qui, lui, ne répugne point à la formule de "communion du Saint-Siège, centre de l'unité », à la différence d'une notable partie de ses collègues. Il prouvera, par la suite, qu'il a une réelle affection respectueuse pour Pie VII, en qui il reconnaîtra toujours l'ancien évêque d'Imola. Mais 
pour l'heure, personne ne songe à cette interprétation. En voulant se démarquer du formulaire trop "servile ", Grégoire a réussi à mécontenter tous ses interlocuteurs. Portalis, furieux, a montré cette lettre à Bonaparte qui interdit sa publication au Moniteur. Caprara triomphe : voilà bien un langage d'« intrus»! Est-ce que l'ancien évêque " national ", par cette sorte de mépris pour «l'arrangement concerté ", ne se rallierait que du bout des lèvres au Concordat, en menaçant de jouer sa propre partition dans le concert de la pacification religieuse? Ce n'est ni la première, ni la dernière fois, que son orgueil mal placé lui joue des tours. Le plus désolant pour tous les acteurs de Concordat, c'est que, selon son habitude, Grégoire donne à sa déclaration la plus grande publicité possible. Elle est immédiatement traduite en plusieurs langues. Les diplomates en poste à Paris en avertissent leurs gouvernements : Stapfer, ami de Grégoire, pour s'en féliciter auprès de Berne; l'ambassadeur Lucchesini s'en indigne auprès du roi de Prusse, sans s'en étonner, car on connaît « ses principes et le souvenir de ses opinions dans le procès du malheureux Louis XVI ne le qualifient point pour un pareil ministère [épiscopal] ».

Le Comité des Évêques réunis où demeurent encore à Paris, Desbois de Rochefort (Somme), Demandre (Doubs), Leblanc de Beaulieu (Seine-Inférieure), Clément (Seine-etOise), croit d'autant plus à un désaveu de leurs propres démissions que la version indirecte de Post multos labores - Portalis croyait l'avoir arrêtée à Paris - a fini par pénétrer dans certains départements portant l'émoi parmi le clergé constitutionnel. On crie à la mauvaise foi du légat, à la «trahison» de Portalis, etc. Bref, la fin du mois d'octobre s'avère chaude dans une situation que personne ne semble plus contrôler, au gré de visites orageuses de certains évêques chez Caprara ${ }^{12}$ qui voudrait bien aboutir à des démissions avec rétractations.

C'est à la suite de ces visites - infructueuses - que les évêques constitutionnels décident d'une mise au point au sein de la confusion générale. Ils donnent leur propre version de cette affaire des démissions dans un long document, Avis des Évêques Réunis, destiné au Premier Consul, le 26 octobre et publié, le 31, dans les Annales de la Religion ${ }^{13}$. Ils annonçaient qu'à ce jour tous les évêques, consacrés depuis 1791, avaient donné une " démission pur et simple, mais volontaire, libre et spontanée de leurs sièges ». Puisque les déclarations avaient été acceptées, accusées de réception par le légat, ils en déduisaient la reconnaissance par Rome de leur légitimité.

« La puissance temporelle et l'autorité pontificale, en exécutant le Concordat vont donc donner la preuve de fait, la plus démonstrative, qu'elles reconnaissent les pontifes nouveaux et qu'elles n'objectent rien à la canonicité des fonctions qu'ils ont exercées ». En parfait symétrique avec le bref Tam multa qui avait réclamé la démission des évêques d'Ancien Régime. À ceci près, que les assermentés exerçant toujours leur charge pastorale, ils en continueraient l'exercice jusqu'à ce que leurs successeurs aient pris possession de leurs diocèses. Périer, par exemple, en avertit ses diocésains de Clermont dans sa lettre pastorale pour le Carême, du 28 janvier $1802{ }^{14}$ :

" Dès que nous avons eu connaissance de la Convention entre notre Saint-Père le Pape et le Gouvernement pour rendre au culte catholique toute sa solennité, nous nous sommes empressés [sic] de céder nos droits [...] afin de concourir de tout notre pouvoir à la réunion de tous les fidèles dans un même bercail et sous un même pasteur [...]. Les circonstances n'ayant pas encore permis de nous remplacer, nous devons, N.T.C.F., continuer l'exercice de nos fonctions et vous porter tous les recours spirituels jusqu'à ce que la Providence nous ait donné un successeur. » 

démissionnaires, la situation allait rebondir avec un fait nouveau: l'incorporation de douze évêques constitutionnels dans le personnel concordataire.

Quels évêques anciens constitutionnels ? À quelles conditions? La crise de mai-juin 1802

41 Caprara, parfaitement au courant des intentions de Bonaparte, se heurte à Rome à « l'insurmontable répugnance » (instructions à Caprara des 1er et 2 décembre 1801) de Pie VII précisant que son devoir serait d'exiger d'eux un temps d'épreuve pour s'assurer "que la résipiscence était sérieuse ». Cependant objecte un légat pressé par les autorités françaises :

«Les circonstances sont telles en France, si ardent est le désir de Sa Sainteté de voir refleurir la religion catholique que s'il pouvait avoir une assurance (sicurezza) morale que tel d'entre eux fût réellement et sincèrement désireux de retourner à l'unité catholique, et si le Premier Consul voulait le nommer à une église, bien qu'avec une extrême douleur, il se plierait à lui complaire ». Avec cinq conditions, toutefois, dont la soumission « aux jugements du Saint-Siège sur toutes les affaires ecclésiastiques de France » entraînant rétractation, soit l'intégralité de la version « indirecte » de Post multos labores.

Dans cette épreuve de force, les constitutionnels ne se rendent pas compte qu'ils ont perdu du crédit parmi les autorités françaises. L'ambassadeur Cacault, à Rome, prévient Portalis que, sur ce point, Pie VII ne cédera jamais : « proclamer en consistoire de tels évêques, c'est sanctionner leur doctrine». Portalis est ainsi fortifié dans sa propre exaspération à la suite de la conduite «insupportable» des constitutionnels au cours d'octobre. D'où ses réticences plutôt inattendues :

«Ce serait, dit-il, compromettre le grand œuvre du rétablissement de la religion que de placer aujourd'hui à la tête des diocèse des sujets qui ne peuvent inspirer que le mépris ou le ridicule. Le cri presque unanime des préfets sur le danger qu'il y aurait à nommer des constitutionnels déconcerte la bonne volonté que l'on aurait de les placer dans la nouvelle organisation ». À peine, concède-t-il, en trouverait-on «trois ou quatre qui ont de l'instruction et des mœurs et qui peuvent être utiles, s'ils savent par leur conduite faire oublier celle de leurs malheureux coopérateurs " (20 février 1802). ${ }^{15}$

On remarque que le Conseiller d'État, habituellement plus nuancé dans ses jugements, reprend pratiquement les «notes" attribuées par l'abbé d'Astros, à sa liste d'épiscopables établie dès octobre 1801. Ce légitimiste camouflé, conseiller de M. Emery plus modéré, a épinglé chaque évêque-citoyen avec des appréciations féroces. Dire que la plupart sont "sans moyens intellectuels et théologiques" ne relève guère de l'honnêteté. Dans un contre-rapport, Talleyrand n'a aucune peine à relever le parti-pris de Portalis :

« Il suffit que les prêtres constitutionnels aient, dans une époque de la Révolution, appartenu au parti patriotique pour que toutes les voix anti-révolutionnaires s'élèvent contre eux ». Le gouvernement veut faire œuvre « de rapprochement et de concorde »; il faut donc qu'il reste objectif. Exclure les constitutionnels «serait diffamer et compromettre dans l'opinion publique tous les résultats de la Révolution ». ${ }^{16}$

Aidé du soutien inespéré de l'abbé Bernier (qui voulait à tout prix sa mitre), Talleyrand raffermit Bonaparte dans sa résolution. Le ministre demandait la nomination de quinze constitutionnels (dont un pour Paris!) et Bonaparte, qui avait annoncé en vouloir douze, renchérit à vingt! Seule concession faite au Pape (après l'avertissement de 
Cacault), Grégoire, «le seul à donner de l'embarras », ne serait pas promu. Bonaparte était pressé d'en finir : tout devait être réglé pour le dimanche 21 mars ou le dimanche 28 , au plus tard, afin qu'on puisse solenniser, dans une cérémonie grandiose, et le Concordat, et la paix d'Amiens.

Restait une incertitude : dans le cas où (et le doute subsistait officiellement) seraient nommés des constitutionnels, que ferait Caprara? Portalis et Bernier furent chargés confidentiellement d'aller sonder le légat. Avec une naïveté toute docile qui dépeint le personnage, le légat eut l'imprudence de répondre qu'il avait le pouvoir de réconcilier ces prélats, selon les instructions reçues de Rome. Les émissaires repartirent rassurer leur maitre, lequel dissimula ses desseins encore quelques jours : les listes soumises au légat ne portaient encore aucun nom "d'intrus». Or, les onze constitutionnels désignés, le 15 mars, par Bonaparte avaient reçu de Portalis, le 24, une circulaire, datée du 17, leur demandant s'ils accepteraient une réconciliation, le gouvernement tenant «à utiliser leurs services ». Parmi les premiers qui répondent favorablement, on voit Lacombe nommé au diocèse considérable (deux départements) d'Angoulême et Belmas au siège prestigieux de Cambrai : deux piliers de la «résistance» prochaine à une rétractation.

Le malheureux légat l'apprend, s'estime joué... et menace d'en référer au Saint-Siège. Nous sommes au plus fort de la crise des évêques « légitimes » en rébellion contre le bref Tam multa. À Paris, on représente à Caprara, pris entre deux feux, qu'il serait " étrange " que le Souverain Pontife écartât des évêques restés fidèles à Rome "tandis qu'on y incorporerait ceux qui avaient travaillé contre elle». Et puis, trêve de tergiversations! Portalis et Bernier viennent, le 27 mars, faire entendre à Caprara que, ou bien il paraitra à Notre-Dame avec tout l'épiscopat concordataire ou bien le Concordat non encore voté par les Assemblées ne sera pas publié. Il est de l'honneur de Caprara de s'être cabré - une réaction qui étonna Bonaparte - protestant que "personne ne désirait la paix plus que lui, mais qu'il ne pouvait rien contre son devoir ». On trouva un compromis qui montre un Bernier manœuvrier.

Le légat devrait dire seulement qu'il lui appartenait, si le Premier Consul en choisissait quelques-uns, de leur donner l'institution et de les "réunir» au corps de l'Église. Avaient disparu les termes - trop malsonnants en France - de réconciliation et de rétractation; plus curieux, la "réunion" était donnée comme devant venir non seulement après la nomination, mais après l'institution canonique elle-même : dans son trouble, le légat ne vit que du feu à la manœuvre de Bernier. Au moins avait-il repris ses esprits lorsque, le 9 avril, lors de sa réception solennelle aux Tuileries, on voulut lui faire dire qu'il ne dérogerait pas aux libertés et privilèges de l'Église gallicane ». La formule fut même insérée au Moniteur comme s'il l'avait prononcée, ce qui entraîna de nouvelles polémiques exégétiques sur le texte - prudent en réalité - du serment qu'avait dû prononcer Caprara.

48 C'est dans les deux premières listes de nominations épiscopales (le 9 et 11 avril) que l'on trouve les dix constitutionnels rejoints un peu plus tard par deux autres, assez neutres: Berdolet (29 avril) et Bécherel ( 5 juillet). Sans nous attarder sur leurs biographies ${ }^{17}$, observons que figure l'ancien " état-major » du second concile national, sauf Grégoire, et d'anciens responsables du Comité des Évêques Réunis, autrement dit ceux contre lesquels Rome était le plus prévenue, selon les dépêches de Consalvi (spécialement celle du 2 décembre 1801). 
49 La Semaine Sainte s'annonçait cruciale. Le jour de Pâques (18 avril), tous les évêques nommés auraient à accompagner le légat au maître-autel de Notre-Dame. Même ceux qui ne seraient pas réconciliés ? À cela, le légat ne pouvait consentir. Il n'avait que cinq jours pour obtenir ces fameuses rétractations, depuis qu'il avait connaissance de la deuxième liste des nominations comprenant des constitutionnels dont trois, surtout, paraissaient redoutables : Lacombe (Angoulême), Reymond (Dijon), Belmas (Cambrai), ils allaient être renforcés par un trio aussi "résistant»: Le Coz (Besançon), Périer (Avignon) et Saurine (Strasbourg).

50 Le Jeudi-Saint (15 avril), vers dix heures, Le Coz, Saurine et Périer se présentèrent chez le légat pour lui demander l'institution canonique, comme le prévoyait le Concordat. Caprara suivant sa propre logique opposa, comme préalable, l'adhésion à la version « indirecte» de Post multos labores. Le groupe la rejeta, comme il fallait s'y attendre. Arrive alors le second groupe composé de Lacombe, Belmas et Leblanc de Beaulieu, ancien curé janséniste du Paris révolutionnaire et farouche opposant à l'évêque constitutionnel Gobel. Cet ancien chanoine de Sainte-Geneviève qui a joué un rôle important en tant que théologien gallican au Comité des Évêques Réunis est un des derniers à avoir remis sa démission d'évêque constitutionnel de Seine-Inférieure. Il a été promu, en avril au siège de Soissons. Son zèle pastoral, de la cure de Saint-Séverin à Paris puis à Soissons, est salué par tous. Le ton monte avec Lacombe qui entraîne le groupe dans un durcissement proche de la surexcitation. Cela n'étonne guère de la part de l'ancien vice-président du second concile national. Ex-père de la Doctrine chrétienne, devenu prêtre-citoyen intransigeant, Dominique Lacombe n'est point un sot, mais, sous prétexte qu'il est bon prédicateur, il met sa faconde méridionale au service d'incorrigibles exagérations verbales et écrites. Pourfendeur furieux du clergé réfractaire, il pense pouvoir tenir la dragée haute à toutes les autorités impliquées dans le Concordat. N'est-il pas promu à la tête d'un des diocèses qui compte plus d'un million d'habitants? Dans cette journée tumultueuse, il en appelle à Portalis qui convoque Bernier, fraîchement sacré évêque d'Orléans. On discute, on négocie, on transige et le subtil Bernier, qui n'en est plus à une «rédaction » près, finit par admettre la contorsion de Lacombe qui, au soir, « proteste » que son « abandon » de la Constitution civile n'était que d'ordre pratique, non d'ordre doctrinal. «En ayant respecté et aimé les dispositions, il continuerait toujours de les respecter et de les aimer ». La formule plaît à certains résistants qui auraient alors signé la formule latine adressée au Pape, fabriquée par Bernier, à l'insu du légat bien sûr ${ }^{18}$... Ils auraient signé cette rétractation toute formelle mais à quelle date?

51 Ici, les versions se brouillent devant les réactions de Caprara auquel Bernier a porté sa formule dans la soirée du Jeudi-Saint. Il faut un peu mentir sur les sentiments exprimés par les réputés repentants. Bernier «supplie, conjure » le légat de prendre la formule en considération. Devant l'inflexibilité de Caprara, à bout d'arguments, Bernier finit par avancer que l'institution canonique ne pourrait être que provisoire... en attendant le jugement définitif du Pape! Balayant cette bizarre science canonique qui autoriserait des institutions canoniques "provisoires ", Caprara maintient son refus... Tout est à reprendre le Vendredi-Saint...

52 La tension a-t-elle été trop forte pour un Caprara qui paraît épuisé ? Il allait finalement céder quand un membre de la légation, Mgr Mazio, supplia, pour sauvegarder l'essentiel, d'émettre deux conditions. La réconciliation des constitutionnels serait publiée par voie de presse et devant deux témoins : Bernier et de Pancemont (Vannes) 
qui était déjà intervenu pour soutenir les droits du Saint-Siège. Bernier promit tout ce que l'on voulait... bien décidé à oublier dès que possible.

Preuve en est sa version, contredite par Lacombe, confirmé dans ses affirmations par Reymond, Le Coz et Belmas. Le trublion d'Angoulême lance une nouvelle bombe, en effet, en publiant dans les Annales de la Religion, du 4 juin, une sorte de lettre ouverte, officiellement adressée à son ami le chanoine Binos. On sait, par sa correspondance, qu'il avait aussi dit son fait à Mgr Brault, évêque de Bayeux, ancien émigré et violemment indisposé contre le clergé ex-assermenté ${ }^{19}$. Voici la version de Lacombe dans ses passages essentiels :

" Nous, évêques gallicans, tenons à nos maximes et à notre liberté. Nous n'avons pas voulu grossir le nombre des ultramontains. Je suis [...] aussi intraitable que la roche qui supporte Montréjeau [son lieu de naissance]. En signant la Constitution civile du clergé, nous n'avons nullement péché; Rome n'a rien à craindre des privilèges de l'Église gallicane [...]. Mais ma vie, mon sang appartiennent à l'Église catholique et je mourrais pour elle [...]. D'ailleurs, si j'ai été choisi comme évêque d'Angoulême et de Périgueux, c'est qu'on me juge orthodoxe et convenable. Enfin, ladite Constitution civile est caduque par le fait du Concordat. Ayant adhéré à ce dernier, quelle raison ne pouvait nous amener à rétracter quoi que ce soit; dire le contraire serait mentir et nous en appelons à Bernier et à Portalis pour témoigner. La formule, que nous avons signée librement, a été rédigée par nous, non par d'autres. Au reste, plein de respect pour le Saint-Siège, je récuse une quelconque absolution qui nous aurait été donnée par le légat et dont nous n'avions aucun besoin. »

Recherchant un éclat, Lacombe déclenche un scandale. Pour une fois, il n'est pas le fruit d'un simple sursaut de mauvaise humeur; il s'inscrit, au contraire, dans le contexte d'événements qui, depuis début mai, font craindre à une rupture du Concordat... Pour des raisons qui restent obscures, la longue dépêche de Caprara, rédigée le jour de Pâques, ne parvint à Rome que le 18 avril. Murat la remit au Pape le 19. Le légat retraçait les événements de la Semaine-Sainte et son impuissance devant la forfaiture de Bernier menaçant de rompre le Concordat si sa propre formule de "rétractation ", imposée aux anciens évêques constitutionnels, n'était pas agréée. La coupe fut pleine lorsque, le 20, un aide de camp apporta le texte du discours prononcé par Portalis au Corps Législatif à propos des Articles Organiques. Pie VII devient encore plus anxieux lorsque, le 5 mai, Consalvi écrivit à Caprara ${ }^{20}$ :

« Tous les journaux de France et, par conséquent, tous ceux d'Italie et des autres pays publient le décret des Consuls qui prescrit l'observation des lois de la République et des libertés gallicanes et [...] renferment le serment de votre Eminence qui comprend les deux choses » ce qui, dans la réalité, était inexact. Et, ajoutait le cardinal Secrétaire d'État, «les journaux d'Allemagne publient les articles organiques comme s'ils faisaient partie du Concordat [...] »

Cette fois, le Saint-Siège se devait de réagir... avec une prudente fermeté. La Congrégation des cardinaux étant entendue, le Pape prononce une importante allocution dans le consistoire du 24 mai. Pie VII avait pour préoccupation de rétablir les faits en publiant, d'une part, les documents ayant trait aux 17 articles du Concordat, à l'exclusion formelle des Articles Organiques, et, d'autre part, le texte original, en latin, du serment du légat, le jour de Pâques. Pie VII énumérait ensuite les bienfaits que le Concordat apportait à la France, mais il demandait " des modifications et des changements opportuns et nécessaires » et expliquait à quelles conditions et en quels termes les évêques constitutionnels avaient été réconciliés. 

l'allocution inspira, dès le 9 , une note diplomatique à l'intention de Cacault chargé de présenter au Saint-Siège des « observations ». On y distinguait deux objets : le premier sur la légalité des Organiques: «Le gouvernement protégera toujours avec force la religion. Mais il défendra aussi ses maximes [gallicanes] parce qu'elles sont la sauvegarde des droits essentiels de la souveraineté ». Le second objet traitait des évêques.

Portalis soulignait dans l'allocution pontificale «le silence profondément gardé sur la conduite des évêques non démissionnaires ». Manière d'accuser l'échec partiel du bref Tam Multa au sujet des évêques d'Ancien Régime. Et plus incisif :

« Parce que l'on parlait des évêques constitutionnels et de l'indulgence dont on usait à leur égard, pourquoi ne pas blâmer la conduite des évêques non démissionnaires qui ne méritent aucune indulgence, qui résistent avec tant de scandale à la voix du chef de la chrétienté et qui foulent au pied tout ce qu'ils doivent à leur patrie ?»

La note de Portalis, qui finirait par être connue du public, suffirait-elle à calmer les esprits? L'allocution du Pape soulevait une tempête de protestations parmi les évêques ex-constitutionnels récemment nommés. En arrivant dans leurs diocèses, ils découvraient des résistances farouches à leur intronisation, principalement dans les régions réfractaires. $\mathrm{Si}$ « des émissaires parcourent les villages [...] si le feu s'allume partout [...]», ces troubles sont imputables à l'allocution de Pie VII, clame Le Coz à Besançon. Leblanc de Beaulieu, depuis Soissons, s'ouvre à Portalis d'un projet de protestation publique contre l'allocution, ce dont le Conseiller d'État le dissuade d'un ton d'autorité. On a vu que Lacombe, à Angoulême, a choisi le mode de la publicité personnelle... et percutante. Il trouve un écho auprès de ses confrères dans les Annales de la Religion du 15 juin ${ }^{21}$. La crise de crédibilité du Concordat, en mai-juin 1802, outre la hiérarchie ecclésiastique, se propage dans les diocèses. De partout parviennent des réclamations de prêtres, anciens constitutionnels, inquiets sur la possibilité de leur réconciliation avec Rome. Malgré le Concordat, certains évêques (Rouen, Bayeux, Rennes, SaintBrieuc, Vannes) exigent pour leur réconciliation la formule maximaliste contenant, entre autre «l'abjuration de la Constitution civile du clergé » considérée par les intéressés comme un abus de pouvoir.

Le 5 mai, Bonaparte avait recommandé aux évêques qui venaient de prêter le serment concordataire de n'exiger "des prêtres d'autre déclaration que de reconnaître le nouvel évêque, d'entrer dans sa communion et de se soumettre au Concordat ». À l'instigation de $\mathrm{M}$. de Pancemont, évêque de Vannes, des prélats "légitimes" objectèrent que ce n'étaient point les conditions fixées par le légat. De nouveau s'engagea, courant mai, une nouvelle bataille des formulaires entre Portalis, préoccupé des exigences d'évêques imposant des formules différentes d'un diocèse à l'autre, et Caprara campant toujours sur la ligne fixée par le Saint-Siège, depuis l'allocution pontificale du 24. Le légat faisait état d'un «scandale général» au reçu d'une «multitude de lettres de tous les départements »; il estimait « en conscience de fixer le mode de réconciliation qui prévienne toute surprise et toute erreur de la part des fidèles». L'indispensable et imaginatif Bernier fut encore chargé de trouver un compromis. Le 1er juin, Caprara finissait par accepter la formule suivante, à l'usage des prêtres républicains demandant leur réconciliation : 
« J'abandonne le bénéfice que j'avais occupé sans l'institution canonique. Je me soumets entièrement aux jugements du Saint-Siège sur les affaires ecclésiastiques de France et je professe une vraie et sincère obéissance au Souverain Pontife et à mon évêque légitime."

61 Irrités par cette perpétuelle mention des "jugements du Saint-Siège ", des prêtres constitutionnels continuèrent de refuser la formule: le Concordat et rien que le Concordat, répétaient-ils. L'évêque Maudru, relégué à Stenay, près de Thionville, ameutait les populations et fondait un «parti » des 200 prêtres constitutionnels de la Meurthe et des Vosges. Protégé de Grégoire et surtout de Le Coz (Besançon), il rédigea une lettre ouverte au légat, au nom des récalcitrants, afin d'obtenir «la levée des censures qu'ils auraient pu encourir, des suspenses et irrégularités dont ils pouvaient être frappés" incriminant les mauvaises manières de Mgr. d'Osmond, évêque concordataire de Nancy ${ }^{22}$.

Après le coup d'éclat public du 4 juin, dû à la plume de Lacombe, la philippique de Maudru étalait au grand jour les troubles dans l'Est, dangereusement relayés en d'autres régions. Le gouvernement ne s'y trompa pas. Le lundi de Pentecôte, 7 juin, Bonaparte dicta à Portalis une longue lettre, fort sévère, pour Mgr d'Osmond. Elle édictait, en fait, une politique générale destinée à mettre un point final à cette péripétie, rémanente de troubles. Ayant souligné « que les affaires actuelles du clergé ne sont le triomphe d'aucun parti, mais la réconciliation de tous ", le Premier Consul tranchait dans le vif :

" [Je sais parfaitement] que les évêques mêmes, qui ont professé et exercé sans l'institution du Saint-Siège, n'ont pas fait eux-mêmes la rétractation; et que le gouvernement regardant un homme qui se rétracte comme un homme déshonoré [23], n'eût certes pas confié l'administration d'un diocèse à un évêque qui se fût rétracté ; qu'enfin, la seule chose qu'ont faite les constitutionnels, c'est de recevoir, avec le respect qu'ils devaient, l'institution canonique; que si tous les prêtres constitutionnels eussent, comme ceux qui ont émigré [cas d'Osmond], craint les échafauds de la Terreur pour se sauver en pays étranger, il ne fût pas resté en France de trace ni même de tradition de religion; et cela est si vrai que beaucoup de prêtres constitutionnels, nommément Gobel, évêque de Paris, sont morts martyrs dans l'exercice de leurs fonctions ; qu'enfin, pour avoir le droit d'aller chercher ce qu'ont fait les prêtres constitutionnels dans les moments de troubles, il fallait y avoir été.»

Indirectement désavoué par cette mercuriale, le légat, après quelques tergiversations, dut enfin acquiescer encore une fois. Le 10 juin, il adressait une circulaire à tous les évêques ayant valeur définitive :

« Je vous ai adressé le 10 mai un décret portant prorogation pour six mois des facultés extraordinaires accordées par le Souverain Pontife Pie VI aux évêques et aux administrateurs des diocèses. D'après la demande que m'en a fait le gouvernement et pour le plus grand bien de la paix, quant à la partie qui concerne la réconciliation des prêtres constitutionnels, vous l'accepterez suivant le mode de réconciliation que je vous trace et que je vous envoie ci-joint [...] ${ }^{24}$

64 Et pour clore ce débat qui avait duré plus d'un mois, ordre était donné à Chaptal, ministre de l'Intérieur, le 8 juin :

« D'écrire une circulaire à tous les préfets pour leur faire connaître qu'on ne doit exiger aucune rétractation ni des évêques constitutionnels, ni des autres. Le passé est passé et les évêques et les préfets ne doivent exiger des prêtres d'autre déclaration que celle qu'ils adhèrent aux lois organiques [sic], qu'ils sont dans la communion de l'évêque nommé par le Premier Consul et institué par le légat du Pape.» 

conflits locaux. On pourrait même, sur le plan sociographique, distinguer un clivage peu souligné. Le zèle de parfaits "préfets violets » n'empêche pas la continuation de vifs ressentiments religieux aux antipodes de la pacification concordataire. L'archevêque Le Coz se mure dans la citadelle bisontine qui n'abrite pas moins de cinq évêques ex-constitutionnels (Seguin; Demandre, du Doubs; Flavigny, de la HauteSaône ; Moïse, du Jura ; et, plus tard, d'Orlodot, de la Sarthe) contre un diocèse, non seulement à majorité réfractaire, mais de sensibilité royaliste ${ }^{25}$. À l'inverse, Brault qui a la bienveillance du préfet, Caffarelli, mène la vie dure aux anciens constitutionnels exilés dans des «sibéries» du Calvados, bien que se montrant très gallican lors du concile de 1811. Il serait loisible de multiplier les exemples : le facteur commun de la loyauté à Napoléon, et donc à l'esprit concordataire, ne préjuge en rien des réactions religieuses des soixante évêques dans leurs diocèses vis-à-vis de chaque camp, réfractaires et constitutionnels.

Quant aux douze évêques ex-constitutionnels, plus ou moins "mal rétractés ", ils restent ce qu'on peut appeler pudiquement une anomalie; ils ont bien reçu leurs brevets d'évêques délivrés par le gouvernement, mais leurs institutions canoniques conservent un caractère précaire. Leurs procès informatifs traînent à Rome, quelquefois suspendus dans le cas de dénonciation notoire de leur déclaration de rétractation. D'où la remise en cause des absolutions qu'aurait conférées le légat. Rome garde en réserve une arme absolue qui continue d'hypothéquer l'œuvre concordataire : la retenue des bulles d'institution. Une situation qui, à l'évidence, ne peut s'éterniser.

Un passé qui ne passe pas ... Pie VII à Paris (novembre-décembre 1804)

D'une plume bien imprudente, Bonaparte avait signifié dans sa directive à Chaptal à l'intention des préfets : «le passé est passé ». Rome allait lui prouver qu'en matière de doctrine, ce passé ne passait pas, ne passerait jamais. Et Bonaparte attachait le plus grand prix à la venue de Pie VII pour son couronnement d'Empereur. Bien des raisons motivaient les réticences du Pape, parfaitement tenu au courant des sérieux coups de canif dans le contrat concordataire. En dépit d'un lourd contentieux, le séducteur avait assuré, promettant mille choses en filigrane, « tout le bien qui résultera pour la religion du voyage que Sa Sainteté est sur le point de faire en France ». Caprara est prévenu et le cardinal Fesch, qui a succédé à Cacault dans le poste d'ambassadeur de France près du Saint-Siège, confirme : une des conditions de la venue à Paris du Saint-Père consiste dans la réconciliation entière et sincère des évêques constitutionnels nommés dans le corps concordataire.

Comme les «non-réconciliés » n'ont jamais fait amende honorable, bien au contraire, on pressent un scénario répétitif de la Semaine-Sainte de 1802, à la notable différence que, maintenant, ils auront affaire au Saint-Père en personne. L'urgence est analogue : en 1802, il faut que tous les évêques nommés entourent le cardinal-légat pour la célébration solennelle de Pâques, la proclamation du Concordat et la célébration de la paix d'Amiens. En 1804, les évêques doivent constituer une assemblée plénière pour le sacre du 2 décembre. Dans les deux cas, les protagonistes disposent d'une semaine pour aboutir à une solution acceptable. 
secrétaire de Grégoire, s'en sert, en janvier 1805, pour établir le « récit historique » des événements, lors du séjour à Paris de Pie VII . Selon cette source, on recensait huit prélats, au maximum, qui passaient pour non rétractés en novembre 1804. Claude Primat, ancien évêque constitutionnel de Lyon, est un cas intéressant en raison de son passé. Pourquoi est-il bien noté par Bernier, comme ayant « des lumières et du zèle »? D’Astros, lui, soulignait son "apostasie » devant le club révolutionnaire de Douai en l'an II. Le fait est incontestable, mais dans quelles conditions? Il est vrai qu'il rentre en grâce auprès du Comité des Évêques Réunis et devient rapidement collaborateur aux Annales de la Religion (2 mai 1795). Si ses collègues avaient eu le moindre doute sur sa rétractation, il n'eût jamais été élu évêque de Rhône-et-Loire (Lyon) en 1798 pour participer, ensuite, au second concile national ${ }^{26}$. L'ancien oratorien (qui a l'appui de Fouché) fait partie de la grande promotion du 9 avril 1802 au titre d'archevêque de Toulouse. Contrairement à beaucoup de ses anciens collègues de la Révolution, il a su faire la part belle aux réfractaires de son diocèse. Il s'était rétracté de son serment constitutionnel dès l'été 1802. Il ira saluer Pie VII sous les murs de Toulouse, le 2 février 1814. Plus contesté est le cas de Leblanc de Beaulieu, évêque concordataire de Soissons. On l'a vu parmi les récalcitrants de la Semaine-Sainte de 1802. Rondeau affirme qu'il a « rendu publique sa propre rétractation en 1804 », avant l'arrivée de Pie VII. En novembre 1804, donc, " on reconnaissait encore huit évêques en France dont la main était vierge et qui n'avaient point souscrit, soit directement, soit indirectement, de formule de rétractation ». Rondeau ajoute cependant que Bécherel, nouvel évêque de Valence, était "suspecté d'avoir signé quelques formules [sic] de soumission aux jugements du Saint-Siège sur les affaires de l'Église de France ».

71 Effectivement, l'évêque de Valence est de ceux qui vont se jeter avec une filiale affection dans les bras de Pie VII, en 1804. Ce normand, ancien évêque constitutionnel de la Manche, a conservé de solides relations avec ses anciens collègues: Marbos, ancien évêque constitutionnel de la Drôme qui, jeune curé, avait connu Bonaparte, officier d'artillerie, le "bon Marbos", devenu conseiller de préfecture, fut réconcilié, en 1819, par Bécherel ; Lefessier, évêque de l'Orne ; Prudhomme, évêque de la Sarthe ; Grégoire, etc. Il resta le " conseiller très écouté » de son ami Périer, évêque d'Avignon. Surtout, il laissa l'administration épiscopale entre les mains de Charles Bisson, évêque constitutionnel du Calvados, qu'il avait appelé auprès de lui, à cause de la persécution par l'évêque de Bayeux, Mgr Brault. Il faut tout de même attendre 1814 pour que Mgr Bécherel, dans son testament spirituel, explicite une profession de foi, jugée trop vague, en la «sainte Église catholique, apostolique et romaine et au Souverain Pontife, successeur de Saint Pierre » :

« Je réprouve et condamne toutes les hérésies et les fausse doctrines condamnées par les conciles et surtout par le concile de Trente et par Notre Saint-Père le Pape Pie VI. J'aime à rappeler ici qu'une des époques les plus consolantes de ma vie est celle où j'ai vu cesser les divisions qui affligeaient l'Église de France ; où moi-même, plein de regrets d'avoir suivi un parti que condamnait l'Église, j'ai soumis ma conduite et j'ai rétracté mes erreurs entre les mains de Notre Saint-Père le Pape Pie VII et reçu les témoignages les plus sensibles de sa tendresse, de sa clémence, de sa bonté paternelle. ${ }^{27}$

72 Il n'en resta pas moins, jusqu'au concile national de 1811, un ferme partisan du gallicanisme impérial. Reste le cas obscur de Marc Berdolet, évêque constitutionnel du Haut-Rhin, traducteur en allemand des actes $d u$ second concile national. Peu encombrant, recommandé par plusieurs autorités civiles, il ne fut promu que dans la deuxième liste du 29 avril 1802, pour le siège d'Aix-la-Chapelle. Grégoire, son ami 
proche, pensait qu'il s'était rétracté en avril 1804: il se plaint à Le Coz de cette "lâcheté» ${ }^{28}$. Il faut croire qu'il n'en était rien, puisque "le Pape, jugeant sa rétractation incomplète, ne le reconnut que le 26 mars $1805{ }^{29}$. De sorte qu'on s'accorde avec Rondeau pour ne reconnaître que six cas d'anciens constitutionnels priés de se réconcilier avec Pie VII à l'hiver 1804. Car l'anomalie subsiste: elle est soulignée par Belmas dans une lettre à Grégoire. En octobre, il certifie que « depuis ce qui s'est passé lors de l'institution, on n'a fait auprès de moi aucune tentative pour me rétracter ${ }^{30}$.

$73 \mathrm{Au}$ nombre de ces «anomalies" vivantes: Le Coz, archevêque de Besançon, et son suffragant, Belmas, évêque de Cambrai ; Périer, évêque d'Avignon ; Saurine, évêque de Strasbourg; Reymond, évêque de Dijon et Lacombe, évêque d'Angoulême. Autant les événements de 1802 sont soigneusement minutés, grâce aux archives d'État et à celles du légat Caprara, autant ceux de 1804 ne prêtent qu'à des « récits » ou des recueils de témoignages. À l'instar de celui de Claude Debertier (1750-1831), qu'il a consigné dans ses Mémoires inédits ${ }^{31}$.

74 L'Auvergnat Claude Debertier méritait mieux que ses insuccès sur le siège de Rodez (Aveyron). Le chanoine Pisani, peu suspect de sympathie envers le clergé constitutionnel, l'estime "esprit positif; il voyait juste et jamais il ne se permit de déguiser sa pensée sous les euphémismes et les hâbleries qu'on rencontre dans la correspondance de plusieurs de ses collègues " ${ }^{32}$. Ce lazariste, supérieur du petit séminaire, exact contemporain de Grégoire, n'avait été élu, le 24 mars 1791, que grâce à la forte abstention dans l'assemblée électorale de Rodez. Maladif, il passe pour bon théologien et solide directeur spirituel. Par ses mœurs, on le croirait janséniste. Il n'est qu'un gallican radical. Ayant épuisé toutes les avanies, malgré sa conduite irréprochable, en Aveyron, il rédige une sorte de testament mystique, en 1795, qui se terminait par ce cinquième article :

« Je tiens irrévocablement aux quatre articles de la déclaration du clergé de France de 1682. En conséquence, je ne regarde comme irréformables que les jugements de l'Église [universelle]. Ainsi, j'ai été, je suis et je serai, avec le secours de Dieu, soumis tout ma vie à tous les jugements qu'elle portera sur les matières de foi, de morale et de discipline."

Grégoire lui témoigne son estime en le faisant entrer au Comité des Évêques Réunis. Toujours prêt à offrir sa démission, il ne fallait pas compter sur lui pour se " soumettre » à la loi concordataire. Dans son testament du 29 mars 1807, il se portait « appelant» de tout, depuis la bulle Unigenitus (1713) jusqu'aux brefs de Pie VI et à Post multos labores de Pie VII. Autorité écoutée pendant le second concile national, il s'était néanmoins opposé à Grégoire sur la question de la liturgie en français. Debertier critiquait aussi certains textes des Évêques Réunis, comme trop éloignés du " langage des Apôtres ». Démissionnaire en 1801, il s'était retiré à Paris. Il continuait une activité pastorale, notamment à Saint-Maur, grâce aux pouvoirs qu'il avait reçus du cardinal de Belloy. On a beaucoup glosé sur une prétendue rétractation ${ }^{33}$. L'archevêque de Paris, Mgr. de Quélen, n'en jugera pas ainsi. Alors qu'il est frappé de paralysie, en 1830, Debertier réclame les derniers sacrements auprès du curé de Saint-Louis-en-l'Isle. Refus de l'archevêque en l'absence d'une rétractation formelle de l'ancien prélat constitutionnel. Mgr. de Quélen en usera de même bientôt à l'égard de Grégoire. On sait combien fut dramatique ce refus des sacrements pour un Grégoire auquel l'archevêque refusa également l'hospitalité d'une église parisienne pour ses obsèques religieuses. La 
scène se renouvellera, à l'identique, lors de la mort de Debertier, le 19 octobre 1831, moins de six mois après les funérailles de Grégoire ${ }^{34}$.

La source Debertier mérite considération : il habite, en effet, sur place, à Paris ; il est un confident de Le Coz qui mène un peu le parti de la résistance ; il vit, à ce moment, avec Molinier, l'ancien évêque des Hautes-Pyrénées, le mentor du remuant Lacombe, évêque d'Angoulême, depuis leurs années communes dans la congrégation de la Doctrine Chrétienne, sans compter la proximité de Grégoire à la tête de son réseau d'informateurs. Enfin, en dépit de ses sympathies gallicanes, il est crédité d'une franche honnêteté intellectuelle. Il reste possible, pour certains points, d'opérer quelques recoupements avec les archives romaines.

Pie VII, accompagné de sept cardinaux dont deux français (Fesch et de Bayane, appelé, plus tard, à jouer un rôle important près du Pape, prisonnier à Savone) est arrivé à la mi-novembre. Le cardinal Antonelli, un zelante, remplace Consalvi auprès du Pape. Caprara lui apprend tout de suite que la plupart des anciens constitutionnels sont déjà arrivés à Paris pour participer aux cérémonies du sacre, comme ils en ont été priés par le Gouvernement. Le Coz est sur place depuis le 15 novembre; il écrit à un cousin de Bretagne «le cardinal, quoique nous ayons eu quelques petites discussions ensemble, ne fait aussi beaucoup d'honnêtetés ${ }^{35}$.

En principe, on pensait, de part et d'autre, aboutir à des réconciliations dans la semaine du 29 novembre, le Pape ayant réaffirmé qu'il n'admettrait aucun constitutionnel non rétracté, lors du 2 décembre. À la première entrevue, le 29, Le Coz se vit présenter un modèle de formulaire, calqué sur la profession de foi de Leblanc de Beaulieu et sur celle de Primat, à l'encre encore fraîche, puisqu'elle ne datait que du 21. Inlassablement, depuis le bref Post multos labores, revenait la phrase litigieuse et décidément insurmontable pour les récalcitrants : «je déclare devant Dieu que je professe adhésion et soumission aux jugements du Saint-Siège sur les affaires ecclésiastiques de France ».

Le 30, cinq des prélats récusaient la formule. Seul, Dominique Lacombe signa en début d'après-midi. On dira désormais qu'il a « la tête affaiblie ». En fait, il a subi une attaque d'apoplexie, le 4 septembre, assez sévère pour qu'on ait craint son décès. Cela n'a pas empêché le pétulant évêque d'Angoulême de prendre la poste pour aller, dit-il, "couronner son Empereur»! Debertier commente la grave inconséquence de son collègue : « Il signe sur ce qu'on lui dit qu'on entendait par le Saint-Siège, le Pape uni à toute l'Église. Il ne lui vint pas non plus à l'esprit qu'en déclarant que, depuis l'institution canonique donnée par le légat, il avait été constamment attaché au grand principe de l'unité catholique, il donnait à entendre qu'il ne l'avait pas été auparavant ». Sermonné par ses collègues, l'évêque revint sur sa signature, en fin de soirée, et finit par signer un texte dont nous n'avons pas la teneur, mais qui, selon Debertier, serait tellement corrigé qu'il en serait devenu informe. Sa mauvaise santé mentale pouvait passer pour une excuse ${ }^{36}$. Le Coz signa, à son tour, en omettant la fameuse phrase sur « les affaires ecclésiastiques de la France». Caprara avait pourtant insisté auprès d'Antonelli : agir en douceur. Le prélat breton avait été pris de front. Il savait que sa déclaration, telle quelle, n'avait aucune chance d'être agréée par le Pape. Caprara, échaudé par deux ans de négociations stériles, avait recommandé de remettre toute l'affaire ente les mains de Napoléon, puisqu'aussi bien c'était à cause de son sacre qu'on ravivait ce pénible débat. Le $\mathrm{Coz}$ sait très bien que les autorités gouvernementales sont fébriles. Le soir du 30, il écrit une lettre à l'Empereur pour préciser le sens qu'il donnait à sa signature, arguant du seul serment qu'il avait prêté 
depuis la Révolution: celui de fidélité au Concordat (y compris, rappelons-le, avec les Articles Organiques qui reconnaissaient la Déclaration des Quatre Articles de 1682). Les autres, «à son imitation, écrit Debertier, et par le conseil de plusieurs ministres, en font autant ».

L'évêque de Strasbourg, Saurine, demeura inflexible. De ce fait, il n'assista point à la cérémonie du sacre; Le Coz non plus. Il profita de ce congé pour reprendre le formulaire et l'amender sérieusement. Le 3 décembre, à huit heures du matin, il se présentait chez Fouché, avec le texte révisé et une lettre pour l'Empereur. Il tenait à ce que soit spécifié, de manière irrévocable :

"Qu'il avait été avant et depuis son institution par le légat dans l'unité catholique, qu'il se soumettait aux jugements du Saint-Siège sur les affaires ecclésiastiques de France en tout ce qui n'était pas contraire au Concordat et à la fidélité due à sa Majesté l'Empereur. »

81 Fouché apprécia l'argument de loyalisme politique et se porta garant du meilleur accueil que lui réserverait l'Empereur. À cette nouvelle, Le Coz, Belmas et Reymond, présents à l'entretien, ne voulurent plus connaître que la formule de leur collègue et revinrent sur leurs signatures du 30 novembre.

Le 13 décembre, « les choses en sont là. On vient tout à l'heure de demander M. Saurine de la part de l'évêque de Vannes, Pansemon [ ${ }^{37}$ q qui est un des agents de la Cour de Rome et qui conduit cette affaire avec le légat et le cardinal Fesch. Celui-ci a avoué que le Pape, avant de se décider à partir de Rome, avait exigé que l'Empereur consentît à ses vues sur le clergé constitutionnel ».

Puisqu'il faut appeler de Rome à l'Empereur, Belmas s'exécute et adresse une missive, le jour même, sur le conseil de Fouché qui a décidément pris le relais de Portalis :

"Sire, l'on vient d'exiger de moi une nouvelle déclaration de mes sentiments relativement à l'unité catholique et à la soumission que tous les fidèles doivent au Saint-Siège. Il m'a été facile d'y souscrire [...]. Ce qu'il y a pour moi de pénible, c'est que l'on ait pu persuader à Sa Sainteté qu'elle avait besoin de cette nouvelle garantie comme si ma conduite n'avait pas justifié constamment la confiance que la première avait dû inspirer. "

Suivent des protestations de sa bonne foi concordataire. Puis cette finale qui pouvait tout remettre en cause aux yeux du Pape :

" Je supplie Votre Majesté d'être bien convaincue que je n'ai rien fait, que je ne ferai jamais rien de contraire à ce que je lui dois, et que je ne me séparerai jamais de la soumission que je professe envers le saint-Siège, les droits qu'assurent aux souverains les coutumes et les libertés de l'Église de France »...

Puissance des Organiques!

Et pour mieux amadouer le Pape, cette lettre du 13 était antidatée du 2, jour du sacre! 38. Le 14, peut-être encouragée par la « reddition » de Belmas, l'Autorité romaine intime aux autres évêques l'ordre de déférer à une troisième formule latine, "dont les expressions sont si amphibologiques que chaque parti peut les attirer en son sens ", dit Debertier en soulignant que Napoléon laisse éclater son mécontentement envers «la petite cour de Rome ». On discute mot à mot les locutions latines, le temps des verbes, etc. ${ }^{39}$. Le 15, Le Coz et Saurine sont convoqués à 5 heures du soir chez Portalis qui les presse d'accepter ce troisième formulaire latin. En vain. Tard le soir, Portalis rend, avec une certaine exaspération, à Le Coz sa formule du 3 et signifie son congé à l'archevêque de Besançon. Le 17, Périer (Avignon) consent soudain à signer la formule, mais dans une traduction française qui comporte encore des retouches : 
«[...] Je suis soumis de cœur et d'esprit aux jugements du saint-Siège apostolique et de l'Église catholique, apostolique et romaine sur les affaires ecclésiastiques de France de la même manière dont l'Église de France l'a toujours été ».

Pour parler comme Debertier, ce "l'Église de France l'a toujours été » recelait une fameuse "amphibologie» qui pouvait laisser intact le passé gallican! Belmas avait montré plus de docilité en se contentant d'adhérer «aux jugements du Saint-Siège et de l'Église romaine ». Cependant, dans les deux cas, on observe ce distinguo, il n'est pas mince, entre le Saint-Siège et l'Église romaine entendue, elle, dans son sens universel. Et, pour les tenants des thèses conciliaristes, on peut toujours faire appel d'un jugement de Rome à l'Église universelle...

Argument théologique que va expliciter Saurine, l'évêque de Strasbourg. Du 18 au 22 décembre, le ballet des derniers évêques récalcitrants continue entre autorités, soit gouvernementales, soit romaines. Le cardinal Antonelli commence à regarder avec plus d'indulgence le légat, au contact des rudes gallicans. On aura remarqué que, depuis le 3 décembre, Antonelli a capitulé sur la question des brefs de Pie VI, condamnant la Constitution civile du clergé et les assermentés. Saurine, intraitable, réveille le débat en allant plus loin que Périer. Nous en sommes, le 22, à la cinquième formule :

« Je professe devant Dieu que je suis soumis aux jugements émanés du Saint-Siège et de l'Église catholique et romaine sur les affaires ecclésiastiques de France ». Et Saurine retranche le mot «émanés ». Pourquoi ? Debertier raconte que cet aprèsmidi du 22, Saurine a expliqué à ses amis qu'il avait opéré ce retranchement afin " qu'on ne pût pas dire qu'il regardait les affaires ecclésiastiques de France comme déjà jugées par l'Église universelle, ne voulant donner son adhésion qu'aux jugements que l'Église prononcerait dans le temps à venir sur les contestations élevées en France au sujet de la Constitution civile du clergé. »

Qu'entend-il au juste par " temps à venir »? Il est peu vraisemblable que Saurine croie encore à la possible réouverture du concile national, brutalement interrompu en 1801. Il n'est pas non plus usité, dans les discours des ex-assermentés, d'invoquer l'adage : «l'Histoire jugera ». En revanche, il n'est pas impossible qu'ils continuent d'espérer qu'avec le temps, Napoléon rétablira les libertés gallicanes au cœur de l'œuvre concordataire, avec le système d'élections ecclésiastiques, ratifiées par le Souverain et l'institution canonique conférée par les archevêques, c'est-à-dire l'essentiel des Observations des membres du Concile sur le Traité de Rome, du 28 août 1801. Dans cette hypothèse, le Concordat devrait avoir un contenu évolutif jusqu'à ce que l'hypothèque romaine soit levée, grâce à l'hégémonie du gallicanisme impérial. Auquel cas, le concile national de 1811 viendrait combler cette attente.

Le Coz, après une nouvelle tergiversation, signe le formulaire adopté par Saurine. Dès lors, l'horizon soudain s'éclaircit. À partir du soir du 22 décembre, le Saint-Père reçoit enfin les « réfractaires ». Jusqu'à la veille de Noël, il a un mot affectueux pour chacun. Lacombe racontera, de retour dans son diocèse, à qui veut l'entendre " qu'il s'est jeté dans les bras du Pape et que le Saint-Père l'a embrassé avec effusion ». Les évêques reçurent enfin leurs bulles, le 17 juin 1805, avec le pallium pour les deux archevêques : Le Coz (Besançon) ${ }^{40}$ et Primat (Toulouse).

1 Ce qui aurait dû être réglé en quelques jours, à la fin de novembre, avait occupé tout un mois de négociations lassantes. Assez rapidement, la résistance du dernier carré des évêques anciens constitutionnels, d'abord conduite par Le Coz, avait été poursuivie, depuis le 3 décembre, par un Saurine dont le caractère rigide était redouté depuis longtemps par ses anciens collègues. Il savait l'ascendant qu'il avait sur eux, plus 
« constitutionnel » que Grégoire, encore plus austère dans ses mœurs et d'un zèle pastoral inégalable sous la Révolution comme sous l'Empire.

Étant donné son caractère fastidieux, répétitif dans son déroulement de 1801 à 1804, cet épisode dont nous n'avons retracé que les traits principaux, paraît bien mineur dans l'histoire du Concordat. D'autant qu'il ne comporte aucun épilogue. Le comportement des évêques anciens constitutionnels, durant le XIXe siècle, ne signalera nulle " conversion » intérieure - bien au contraire - au moins jusqu'au concile national de 1811, nouvelle pierre d'achoppement. Et, au premier degré du moins, on est tenté de conclure à un entêtement plutôt stupide des intéressés, au risque de compromettre un Concordat, lui-même fruit de négociations laborieuses.

Pourtant, ce dossier présente plusieurs intérêts. Avant tout, il entraîne une révision de l'historiographie classique. La plupart des auteurs laissent penser que les anciens constitutionnels sont entrés, sans difficulté, dans l'épiscopat concordataire. Sous prétexte qu'ils reçoivent l'institution canonique dès avril 1802 , on ne dit guère dans quelles conditions insolites. Silence aussi sur cette "anomalie » d'évêques privés de leurs bulles au mépris du droit canonique, ce qui n'échappe pas, néanmoins, aux différents « partis » du clergé et des populations des diocèses ${ }^{41}$. Personne n'insiste sur le bref Post multos labores, ses différents «versions", source principale des embrouillements postérieurs.

De là, une question jaillit : à qui attribuer les responsabilités d'une situation quasi bloquée pendant trois ans, en dépit d'interventions des autorités au cours de journées fertiles en rebondissements?

Il est facile de pousser à la caricature : la faiblesse du septuagénaire cardinal JeanBaptiste Caprara face à la roublardise de l'abbé Étienne-Alexandre Bernier appuyé par Fouché et Talleyrand, sinon Portalis qui est resté, le plus possible, l'œil rivé sur les articles 3 et 4 du Concordat, par lesquels le Premier Consul nomme les évêques et le Pape confère ensuite l'institution canonique (sans objection?) «suivant les formes établies par rapport à la France » (gallicane ?). En admettant que l'incorporation des évêques anciens constitutionnels survienne de façon imprévue, Napoléon Bonaparte n'a-t-il pas saisi ainsi l'occasion de se servir d'eux, acquis à sa politique, comme d'un banc d'essai d'une pratique concordataire qui inclurait bien la Convention et les Articles Organiques reconnaissant les fameuses «libertés gallicanes»? Caprara, plus fin qu'on ne le croit, informe... et avertit le Secrétaire d'État Consalvi dans une dépêche du 5 décembre 1802, donc après la première crise de mai-juin :

« On fait sentir ici [à Paris] que Rome ayant obtenu la publication du Concordat, chose qu'elle désirait vivement, ne s'occupe plus maintenant que de ce qui peut flatter ses inserts et qu'elle ne veut pas, même par reconnaissance, répondre aux désirs d'un gouvernement envers lequel elle se trouve avoir tant d'obligations et qui lui fait sentir, pourtant, la nécessité où il est d'effectuer les changements qu'il demande. $»^{42}$

Autrement dit, Rome doit savoir faire des concessions. Dans le cas des anciens constitutionnels, elles seront exorbitantes. Au nom de la doctrine et de la foi, le bref Post multo labores, en 1801, exigeait des "schismatiques ", démissions, rétractations et absolutions pour purger tout le passé révolutionnaire. Caprara avait compris qu'on lui avait ainsi confié une mission impossible. En 1804, le cardinal Antonelli, ultramontain intransigeant, était obligé, à son tour, de guerre lasse, d'accepter les déclarations faites, 
si l'on peut dire, sur mesure, au cas par cas des six irréductibles. Il n'est plus question de rétractation ni d'absolution. Post multo labores a fait long feu.

Beaucoup de ces anciens constitutionnels s'en vanteront au long de leur épiscopat concordataire. Faut-il les accuser d'un double langage? Le doyen Latreille n'était pas loin de le penser : «Le sort des formulaires [écrit-il] n'est-il point de se prêter à toutes les interprétations et d'autoriser plus d'une restriction mentale?", songeant probablement aux suites de la bulle Unigenitus de 1713. Mgr. Delacroix emploie une formule analogue: "C'est le sort des formules que d'être interprétées de façons différentes et de recevoir du contexte des faits une signification que le sens obvie des mots ne leur donne point ${ }^{43}$. Une interprétation laxiste que justement refusaient les républicains, trop échaudés par les serments successifs.

Critiquables par d'autres aspects, les anciens constitutionnels ont épluché, disséqué les formules, parfois mot à mot, précisément pour que l'on ne puisse leur reprocher leur mauvaise foi. Ils ont mis leur honneur à rester «invariables dans leur manière de penser ", souligne Grégoire en opposant les "variations » de Rome qui, par là même, leur a imposé une paix carthaginoise sous couvert de pacification concordataire. Car, continue Grégoire, « ou la rétractation est un acte commandé par la religion, et alors vous êtes criminels de ne pas insister; ou elle n'est pas commandée et vous êtes criminels de la demander. Cette alternative est un filet qui vous enveloppe et qui atteste de votre mauvaise foi ${ }^{44}$.

\section{NOTES}

1.Cité par René SCHNEIDER « la réception du Concordat dans les deux diocèses (Strasbourg et Metz) et sa continuité » dans Le Bicentenaire du Concordat, actes du colloque de sept. 2001, Mgr. Joseph DoRÉ et Mgr. Pierre RAFFIN (dir.), Strasbourg, 2002, p. 133.

2.Simon DelaCroIX, La réorganisation de l'Église de France après la Révolution (18011809), t. 1, Les nominations d'évêques et la liquidation du passé, Paris, 1962 ; liste nominative des évêques constitutionnels, pp. 105-106 ; liste nominative des évêques légitimes opposants au Concordat, pp. 111-113.

3.Rodney J. DEAN, L'Église constitutionnelle, Napoléon et le Concordat de 1801, Paris, chez l'Auteur, 2004, 752 p. Diffuseur, Picard, 82 rue Bonaparte, 75006 Paris - Ouvrage le mieux documenté, quoique d'une lecture difficile, cf. pp. 643-691.

4.Annales de la Religion, périodique des constitutionnels, t. XIII, pp. 528-529.

5.Alfred Boulay de La MeurTHE, Documents sur la négociation du Concordat..., t. III pp. 470-471.

6.Lettre pastorale du citoyen Grégoire, évêque de Blois pour annoncer sa démission..., op. cit., p. 18.

7.De l'Église gallicane dans son rapport avec le Souverain Pontife, Paris, 1821, p. 11. 8.Bibl. Soc. de Port-Royal, coll. Grégoire vol. 108 : on trouve encore une invitation de Bonaparte à dîner à cinq heures, pour le 15 janvier 1802. 
9.Histoire des sectes religieuses, 2e édit. 1825, t. 2, p. 454. Avec le titre du bref, version directe : Sanctissimi domini nostri Pie VII, pont. max. epistolae ad principes viros et alios pontificatus sui anno 1 et 2 , fol. 91 et 92 .

10.Lettre pastorale..., op. cit., p. 5.

11.A. N., AF IV 1906 (légation Caprara) : soupçons et critiques des théologiens romains sur les formulaires reçus. Cf. chanoine Léon MAHIEU, Mgr. Louis Belmas, Paris, 2 vol., 1934, t. 1 , pp. 115-116.

12.En janvier 1802, un correspondant des Annales de la Religion (t. XIV, p. 331), écrit qu'à Rome, la version indirecte de Post multos labores a « choqué les gens de bien. Jusqu'en décembre dernier, on ignorait le prétendu bref que Spina a envoyé à quelques évêques constitutionnels. L'analyse qu'on a dressée de cette pièce informe, telle qu'elle a été dénoncée au gouvernement français, a choqué tous les gens de bien. On en a trouvé le langage tout à fait étrange et qui surpasse toute imagination ».

13.Annales de la religion du 31 octobre 1801 - cf. BoulaY, op. cit. t. IV, pp. 168-174. À resituer dans la correspondance Caprara, A. N., AF IV 1891, registre des démissions prétendues des évêques constitutionnels. Les 59 évêques concernés avaient tous remis leur démission à la date du 26 octobre, sauf Lafont de Savine, évêque de Viviers, devenu totalement marginal, cf. Bernard Plongeron, art. Lafont de Savine dans Dic. Hist. et Géo. Ecclésiastiques (à paraître).

14.Albert DuRAND, Un prélat constitutionnel, Jean-Francois Périer 1740-1824, Paris, 1902, pp. 266-267.

15.Boulay, op. cit., t. V, pp. 200-208.

16.Id., pp. 231-253. On retrouve l'écho de ces débats sur les promotions A. N., AF IV 1044.

17.Jacques-Olivier Boudon, Les élites religieuses à l'époque de Napoléon. Dictionnaire des évêques et vicaires généraux du Premier Empire, Paris, 2002.

18.Cf. le texte d'un latin alambiqué dans Léon MAHIEU, op. cit., t. I, pp. 131-132.

19.Jean GÉRARD, La vie ... de Dominique Lacombe, Paris, 1983, pp. 79-80.

20.Simon Delacroix, op. cit., pp. 305 et suivantes.

21.Annales de la Religion, t. XV, pp. 217-228.

22.La situation de Maudru devient tellement intenable à Stenay que Grégoire et le vicaire général Grappin lui conseillaient en 1813 de venir se réfugier à Besançon auprès de l'ami Le Coz ; cf. Bernard Plongeron, Dom Grappin, correspondant de l'abbé Grégoire, (1796 - 1830), Paris, 1969, pp. 83-84 et passim.

23. Ce sont les mots mêmes de Grégoire, cf. note 10 .

24.Simon Delacroix, op. cit., p. 331, note 4.

25.Les tensions politico-religieuses sous l'épiscopat de Le Coz sont rapportées en détail par Dom Grappin qui logea chez Grégoire pendant le second concile national. Vicaire général de l'archevêque, Grappin entretient à ce sujet une intéressante correspondance avec Grégoire, cf. Bernard PlONGERON, op. cit., note 22.

26. Chanoine C. LOOTEN, « Lettres de Primat, évêque constitutionnel du Nord ... », dans Annales du Comité Flamand de France, t. XLI, 1936, 297 p.

27.Jean BINDET, François Bécherel (1732 - 1815), Coutances, 2e édit. 1971, p. 45.

28. Léonce Pingaud, Correspondance de Le Coz et de Grégoire, Besançon, 1906, p. 45.

29.Jacques-Olivier Boudon, op. cit., p. 70.

30.Bibl. Soc. de Port-Royal, correspondance Grégoire, carton Nord. 
31.Ibidem, recueils Girard, ms Debertier, t. IV et t. V « Cause importante à juger ou la cause du clergé constitutionnel débattue et soumise à l'Église catholique », 25 p. in folio. Cf. Bernard PLONGERON « Éclaircissements sur les rétractations d'évêques constitutionnels en 1804 », Revue de l'Institut Napoléon, n 111, avril 1969, p. 99. 32.Paul PISANI, Répertoire biographique de l'épiscopat constitutionnel (1791-1802), Paris, 1907, pp. 377-382.

33.A. C. SABATIÉ, Debertier, évêque constitutionnel et le clergé de Rodez, Paris, 1912, p. 448.

34.Cf. la lettre de Mgr. de Quelen, en date du 11 mai 1831, faisant état du précédent, à la suite du cas Debertier, pour refuser les derniers sacrements à Grégoire, dans CEuvres de l'abbé Grégoire, édit. EDHIS, 1977, t. XIV, pp. 361-362.

35.Alfred RousseL, Un évêque assermenté, Le Coz (1790-1802), métropolitain du NordOuest, Paris, 1898, p. 479.

36.Son dernier biographe est dans l'erreur, en affirmant que « Lacombe signa sans hésiter » (Jean GÉRARD, op. cit., p. 93).

37.Mgr. MAINAUD de PANCEMONT (1756-1807), ancien curé réfractaire de Saint-Sulpice à Paris, évêque de Vannes, le 9 avril 1802, représentant M. Emery, supérieur général de Saint-Sulpice, joue un rôle important dans la réorganisation concordataire. Il avait été désigné, nous l'avons vu, avec Bernier pour recevoir la rétractation des évêques constitutionnels en 1802.

38. Chanoine Léon MAHIEU, op. cit., texte cité pp. 357-358.

39.Le texte entier figure dans Bernard PLONGERON, « Éclaircissements sur les rétractations d'évêques constitutionnels », art. cit., p. 102.

40.Bernard Plongeron, Dom Grappin ..., op. cit., lettre à Grégoire du 9 décembre 1805, p. 59.

41.Cf. les réactions du clergé alsacien dans Réponse à $M$. Saurine, évêque de Strasbourg, dans Simon Delacroix, op. cit., p. 347.

42.A. N., F19, 1922.

43.A. LATREILlE, Napoléon et le Saint-Siège, Paris, 1935, p. 359 ; Simon DELACROIX, op. cit., p. 354.

44.Henri Grégoire, Mémoires, Paris, Édit de Santé, 1989, p. 162.

\section{RÉSUMÉS}

Alors que Rome continue d'ignorer ces « schismatiques ", Bonaparte veut incorporer certains des évêques ex-assermentés dans le personnel concordataire. Pie VII semble s'incliner en promulguant le bref Post multos labores (juillet 1801), généralement oublié par l'histoire officielle. Ce document à la genèse compliquée impose de telles conditions aux anciens prélats républicains que ceux-ci se rebellent et mettent Rome et Paris au bord de la rupture en deux grandes crises : 1802 et 1804 .

Se sont-ils finalement rétractés, par rapport à leur passé révolutionnaire, étant en fonctions concordataires? Le débat demeure ; il met au jour un gallicanisme intransigeant qui persistera, chez nombre d'évêques, jusqu'à la nouvelle crise concordataire de 1820-1822. 
The Resistance oh the Former Constitutional Bishops to the Concordat (1801) While Rome continued to ignore these «schismatics», Bonaparte intended to include in the concordat clergy some of the bishops who had sworn allegiance to the constitutional church. Pius VII seemed ready to yield in promulgating the brief Post multos labores (July 1801), often forgotten in official histories. This document, which had a complex genesis, imposed such stringent conditions on the former republican prelates that they rebelled and brought relations between Rome and Paris to breaking point in two great crises: 1802 and 1804. Did they finally retract and disavow their revolutionary past in accepting concordat posts? The matter remains open to discussion. It reveals a stubborn strain of gallicanism which persisted, in the case of several bishops, until the next concordat crisis of 1820-1822.

INDEX

Mots-clés : révolution, Bonaparte, concordat, gallicanisme, épiscopat constitutionnel, Pie VII, Grégoire, Portalis, Bernier (abbé), Fouché, Talleyrand, Consalvi (cardinal)

\section{AUTEUR}

\section{BERNARD PLONGERON}

CNRS - Institut Catholique de Paris, 36 rue Saint-Placide, 75006 Paris 